Rachelle Renaud, originaire de Windsor, Ontario, habite à Montréal depuis 1992. Elle est poète, romancière et nouvelliste. Ses textes ont déjà paru dans Arcade, Moebius, Les saisons littéraires, Rupture, la revue des 3 Amériques et $X Y Z$ la revue de la nouvelle. Son premier roman Le roman d'Éléonore (VLB éditeur, 1996) lui a mérité le Prix Jacques-Poirier-Outaouais 1996. Son recueil de nouvelles L'amour en personne est paru au Nordir en octobre 1998.

\title{
3
}

\section{Chocs légers}

\section{D} ans une vie antérieure, elle a dû être un ver de terre.

Autrement d'où venait cette voracité de vivre qui la poussait à frayer son chemin dans le noir le plus absolu et à embarquer dans des histoires sans queue ni tête? Et d'où provenait cette sensibilité aigüe qui lui traversait le corps, déclenchée par le moindre petit mouvement environnant?

Parfois elle avait le malheur d'être debout lorsque cela se produisait. Un avion survolait la maison, vrombissant, déchirant le ciel. Un camion chargé de marchandises passait en trombe. Elle tendait le bras instinctivement pour saisir le premier cadre de porte à portée de main. Comme ça, les vitres avaient beau frémir, les fondations vibrer sourdement, elle tenait bon, gardait son équilibre. Ce genre de tremblement souterrain pouvait se faire sentir n'importe quand, elle restait donc sur ses gardes, question d'aller à l'encontre du choc des choses.

A tout instant, elle se retrouvait en plein dedans, ballottée, happée par un véritable raz-de-marée, le mainstream de la vie, la vraie, celle qui se vivait à deux et, avec un peu de chance, en amoureux. Aucun voeu prononcé devant témoins, aucune alliance échangée en guise de promesse, n'importe, son conjoint et elle filaient le parfait bonheur, ça se voyait, ça se sentait, leurs amis s'en réjouissaient ou en étaient vertement jaloux. C'était comme ça, ils étaient tout simplement bien ensemble, liés par une tendresse palpable, tissés serré dans un bonheur odorant. Bref, ils formaient un couple heureux.

- Ne m'attends pas pour le souper, j'ai affaire au nord de la ville. Un gros client. Ce soir, ça passe ou ça casse. À plus tard, ma chérie. Beaux bisous. 


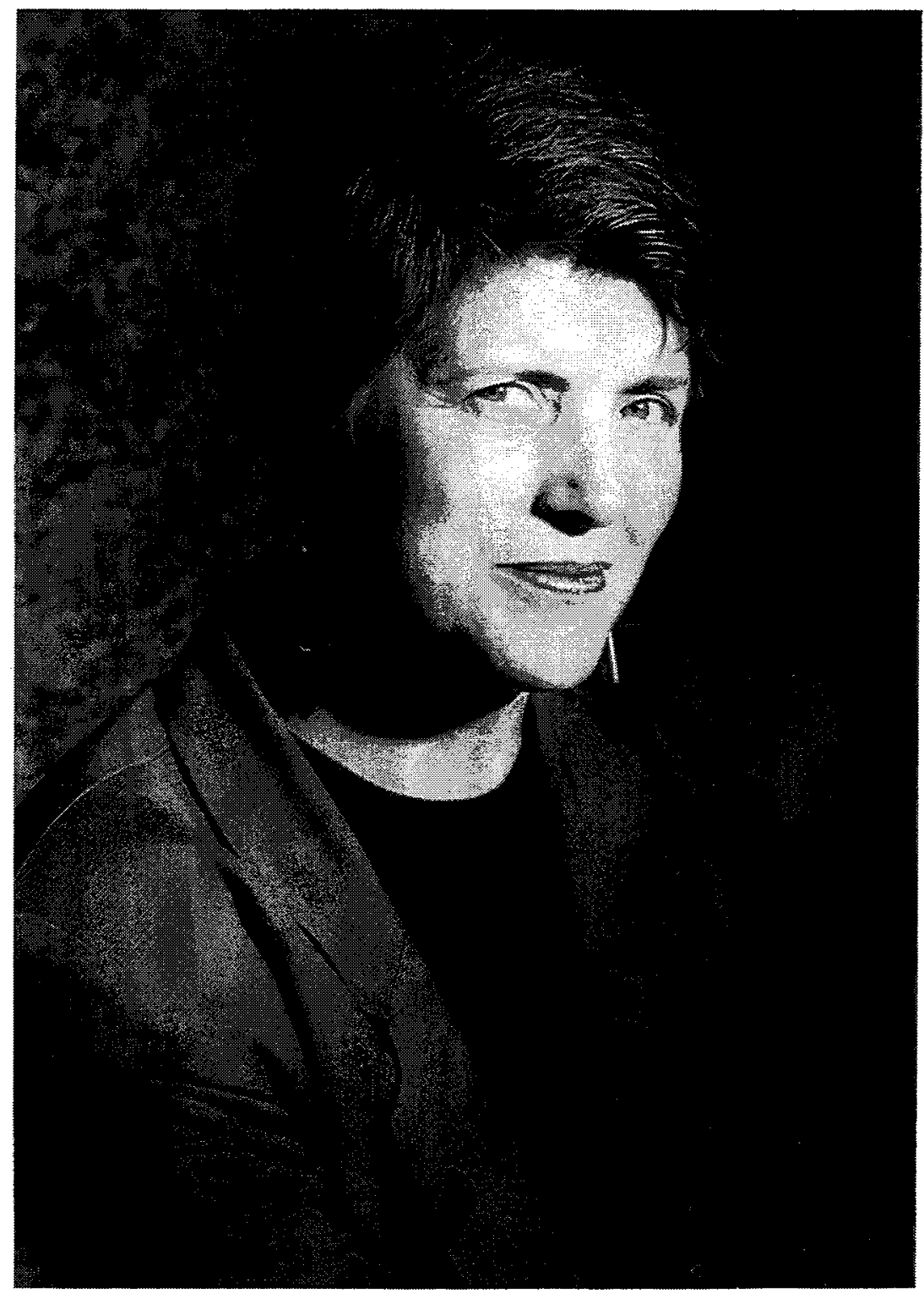

Rachelle Renaud. (Photo: Josée Lambert) 
Message-mitraillette, encore un autre, enregistré sur le répondeur, expédié d'une voix pressée, avec un mot de la fin à faire chavirer le coeur le plus endurci.

C'est tout à fait réussi d'ailleurs, la cible, atteinte de plein fouet, exécute subito presto une affreuse série de trébuchements saccadés. Puis arrive la chute, la bête s'écroule de tout son long dans un dernier mouvement de désir, mais rien à faire, le corps ne suit pas, se recroqueville drôlement tout comme à sa naissance, et dans ce bref instant tout est encore neuf, le monde reste à parcourir, la vie à découvrir, tout cela l'attend impatiemment, elle sera au rendez-vous sans faute, si seulement elle pouvait retrouver ses forces, se tenir debout sur ces pattes qui font, allez savoir pourquoi, les mortes. Sans oublier ce feu froid qui se répand dans sa poitrine, ce goût de plomb qu'elle a à la bouche.

Il faut dire que ce sentiment de défaillance, de défaite absolue, elle en a l'habitude. Elle tente de reprendre sur elle, les choses s'arrangeront, elles finissent toujours par s'arranger. Après tout, ce n'est pas la première fois. Dans un simple petit quart d'heure, tout rentrera dans l'ordre. Comme à l'accoutumée, elle prendra l'apéro, puis le souper en solo. Un simple repas au menu ce soir: pâtes Carbonara, vin rouge, salade César. Elle écoutera également du Debussy, décidément un choix pas sage, compte tenu des circonstances. Ça risque de très mal finir, mais elle s'en fout, ouvre la bouteille de vin, remplit sa coupe qu'elle boira jusqu'à la lie. Sachant que sa barque finira engloutie tout comme la cathédrale.

Au fond, elle ne sait pour quelle raison elle se met dans de tels états. Leur belle histoire d'amour est solide comme le roc et la maison en est l'image toute crachée. Sous son toit, ils se sentent au chaud et au sec, à l'abri des intempéries. Les assises sont sûres, la charpente porteuse de bien-être et de sérénité. C'est quand même remarquable. Leur amour tient bon malgré tout. Malgré le poids immensurable $(x+y)$ de leurs bagages respectifs, malgré le déséquilibre assez dramatique de leurs âges. Tout comme la maison, d'ailleurs, sise sur la glaise qui est de caractère on ne peut plus changeant et volontaire. Les plaques tectoniques pouvaient se livrer aveuglément à leur jeu à des centaines de kilomètres de là, l'île où ils vivaient demeurait en place.

Reste qu'ils habitent une zone cotée 4 en ce qui a trait aux tremblements de terre. Bref, quelque part au fin fond du fleuve, se cache un dieu ancien et sauvage qui ne respire pas par le nez, qui se bute obstinément contre son sort et le leur, trop heureux, trop beau. Personne n'en souffle mot, surtout les météorologues, mais ce dieu jaloux tient les habitants en otages. Un jour ou l'autre, serait-ce demain, il les fera tressaillir et tout sautera.

Et que dire d'autres indices encore plus tangibles? Elle prend son verre de vin et se dirige lentement, machinalement, vers le salon. Au mur, il y a cette fissure 
mystérieuse qu'elle a vue comme par hasard l'autre jour. Elle examine de plus près la fêlure, suit sa cassure du doigt. Presque invisible à l'oeil nu, cette fissuration trahit le vrai état des choses. Le plâtre ancien, lisse comme sa main, est dense et compacte. Mais le danger réside dans sa capacité de s'étirer déraisonnablement loin. Serait-ce le cas pour la structure elle-même? Un seul geste, un seul glissement maladroit, une poutre flanche. Un jour, une nuit, le tout s'effondrera sous leurs pieds, malgré les pleurs et les hauts cris. Ou pire encore, surviendra quelque chose de plus sournois mais tout à fait prévisible: aura lieu un simple relâchement, un fléchissement des solives. Tous ces noeuds lâchent déjà leur soupir de sève car les solives n'en peuvent tout simplement plus de la charge imposée, de la raideur (leur seule raison d'être) et de la rude tâche, ingrate et essentielle, qui est la leur: tenir et ne jamais cesser de tenir. Ce n'est qu'une question de temps, la fatigue s'empare des solives les plus robustes, c'est dans l'ordre des choses. Telle la chair qui, sujette à l'effet de la gravité et de l'âge, tombe peu à peu vers le bas, puis s'assouplit petit à petit avant de lâcher prise pour de bon. La solive fléchit, la chair se flétrit.

La maison a beau être belle, elle porte des rides. Le toit est à refaire, la cheminée ne tiendra pas l'hiver. À savoir la cheminée si chancelante, le loup du conte en rirait de tous ses crocs. Les trois petits cochons ne peuvent rien contre le vilain loup.

L'autre soir elle a préparé des côtelettes de porc. Son amoureux, humant le fumet, a retroussé le nez. Fils de boucher, il en sait long sur les coupes de viande et fait un festin de ce qu'on appelle les bas morceaux.

- Ça sent fort, chère! C'est que, comment dire, cette bête a eu des petits...

Puis, plus tard, en goûtant à cette chair tendre, il est resté agréablement surpris. Il trouva cela bon, expliquant que c'est souvent le cas: les toxines partent avec la fumée.

- Oui, c'est vachement bon, dit-il.

Il va de soi, sa femme considéra le terme comme étant très mal choisi. Une belle truie qui a eu des petits n'est quand même pas une vache. Puis elle eut un mal infini à prendre la prochaine bouchée. Par malheur, elle avait également servi une salade aux pommes. L'idée lui vint, impossible de la rayer de son esprit, de la pomme qu'on force entre les mâchoires du cochon de lait, délice des rois et haut placés. Elle ne saurait dire pourquoi, elle tombe dans les contes de fées comme d'autres tombent dans les pommes.

«Il était une fois une maison de rêve. Toute cette rue d'ailleurs était bordée de maisons proprettes et parfaitement d'équerre. Les propriétaires de cette maison, tout comme leurs rosiers, se la coulaient douce. Le malheur fut qu'ils ne savaient pratiquement rien sur l'entretien des rosiers. Survinrent les sauvageons, touffus et 
traîtres au bout desquels, chaque jour, poussaient d'autres jolis bourgeons.

"N'importe quel fou aurait pu prédire ce qui allait arriver. Même le chien du voisin, Finitude de son nom, flaira le danger. Sur le qui-vive, le chien regardait la voisine sortir le matin, souriante et rayonnante, cueillir quelques roses. Seul le chien s'affolait à voir les petits tas d'excréments s'empiler autour, toujours plus hauts, régulièrement déposés par un matou qui rôdait la nuit et qui, de toute évidence, avait une crotte sur le coeur. Si le chien avait pu mettre la patte dessus, tout aurait été comme avant. Le hic, le canin vivait au troisième et n'y pouvait rien, sauf constater la précarité des choses vivant au ras du sol.

"Une nuit d'octobre, tomba une neige précoce, les roses gelèrent et ce fut la fin. Le matou ne rôdait plus dans les parages, mais hélas, finie la belle saison des amours. Et bien entendu, plus question de cueillir de roses pour garnir la table."

La table du salon, étale et désormais nue de fleurs, s'érige entre elle et la fine fissure au mur.

Sa décision est prise. Elle plantera un seul clou, gros comme le doigt, dans cette fêlure microscopique. Elle le fera doucement et délibérément, tout comme son cher mari enfonce sa tige tendre dans le creux chaud de sa corolle. Puis elle regardera la plaie s'étendre encore un peu, plus qu'hier, moins que demain. Elle aura à cacher les dégâts en y accrochant de quoi. Peut-être serait-ce le certificat de meilleur vendeur de l'année dont se vantait son mari à tout bout de champ, à tout venant. Ou alors la toute dernière photo d'école de son fils qui semait la pagaille chaque fois qu'il passait du temps avec son cher père. Ou encore, oui, pourquoi pas, la toile de son ancienne blonde qu'il tenait à tout prix garder et qui traînait, telle une jarretelle de mauvais goût, dans l'atelier. Enfin, quoi qu'elle choisisse pour couvrir la blessure infligée, son mari en sera ravi, la croyant guérie de sa jalousie.

On ne peut rien pour les aveugles. Quand l'homme rentre, la femme rampe et il est le seul à ne pas s'en rendre compte. N'importe, ce clou planté au bon endroit fera son chemin, tel un ver qui se déplace en secret, vrillant son chemin dans la terre meuble et gobant tout sur son passage.

L'idée lui était venue en accomplissant une tâche routinière qui ne lui plaisait guère. Prise d'un grand frisson en touchant un ver desséché dans les poches du fiston, elle décida que là n'en serait pas sa fin. 